\title{
Exploring the MEN1 dependent modulation of caspase 8 and caspase 3 in human pancreatic and murine embryo fibroblast cells
}

\author{
Nele Wagener ${ }^{1,2} \cdot$ Malte Buchholz $^{3} \cdot$ Philippe Bertolino ${ }^{4} \cdot$ Chang X. Zhang $^{4} \cdot$ Pietro Di Fazio $^{1}$ (D)
}

Accepted: 19 November 2021 / Published online: 8 December 2021

(c) The Author(s) 2021

\begin{abstract}
MEN1 mutation causes pancreatic neuroendocrine neoplasia and benign malignancies of the parathyroid, the adrenal cortex and pituitary gland. The transcriptional activity of its product menin promotes the expression of genes deputed to several cellular mechanism including cell death. Here, we focused on its implication in the activation of the initiator and executioner caspases after staurosporine mediated cell death in 2D and 3D human and murine cell models. The administration of staurosporine, a well-known inducer of apoptotic cell death, caused a significant reduction of BON1, QGP1 and HPSC2.2 cell viability. The transient knockdown of MEN1, performed by using a specific siRNA, caused a significant down-regulation of CDKN1A and TP53 transcripts. The treatment with $1 \mu \mathrm{M}$ of staurosporine caused also a significant down-regulation of MEN1 and was able to restore the basal expression of TP53 only in QGP1 cells. Transient or permanent MEN1 inactivation caused a decrease of caspase 8 activity in BON1, HPSC2.2 cells and $M E N 1^{-/-}$MEFs treated with staurosporine. Caspase 3/7 activity was suppressed after administration of staurosporine in MENI knocked down HPSC2.2 and $M E N 1^{-/-}$MEFs as well. The cleaved caspase 8 and caspase 3 decreased in human cells after $M E N 1$ knockdown and in $M E N 1^{-/-}$MEFs. The treatment with staurosporine caused a reduction of the size of $\mathrm{MENI}^{+/+} \mathrm{MEFs}$ spheroids. Instead, $\mathrm{MENI}^{-{ }^{--}} \mathrm{MEFs}$ spheroids did not show any significant reduction of their size. In conclusion, MENI controls the activity of the initiator caspase 8 and the executioner caspase 3 in human and murine cells. Restoring of a functional MEN1 and interfering with the apoptotic mechanism could represent a future strategy for the treatment of MENI-related malignancies.
\end{abstract}

Keywords MEN1 $\cdot$ Caspases $\cdot$ Cell death $\cdot$ Spheroids $\cdot$ Pancreatic neuroendocrine neoplasia

\section{Introduction}

Multiple endocrine neoplasia type 1 (MEN1) is a rare inherited tumour syndrome, causing different types of neuroendocrine malignancies in the pituitary gland, the pancreas, and

Pietro Di Fazio

difazio@med.uni-marburg.de

1 Department of Visceral Thoracic and Vascular Surgery, Philipps University Marburg, Baldingerstrasse, 35043 Marburg, Germany

2 Department of Trauma Surgery, Orthopaedics and Plastic Surgery, University Medical Center Goettingen, Robert-Koch-Str. 40, 37099 Göttingen, Germany

3 Department of Gastroenterology, Endocrinology and Metabolism, Philipps-University Marburg, 35043 Marburg, Germany

4 Cancer Research Center of Lyon CRCL, French Institute of Health and Medical Research, 69008 Lyon, France the parathyroid glands [1,2]. MENI has been discovered the mostly frequent mutated gene in pancreatic neuroendocrine tumors [3, 4] and almost all of them are family related [5]. It localizes to chromosome 11q13 and consists of 10 exons encoding a 610 -amino-acid protein called menin. Menin is ubiquitously expressed and is predominantly located in the nucleus in non-dividing cells [6]. It shows no homology with other known proteins and the mechanism by which its loss of function leads to MEN1 is still unclear. Menin interacts as a key scaffold protein cross talking with different transcription genes and interplaying with multiple different signal pathways [7]. Menin interacts also with transcription factors, such as activating protein-1 (AP-1), JunD, nuclear factor- $\kappa \mathrm{B}(\mathrm{NF}-\kappa \mathrm{B}), \beta$-catenin, mothers against decapentaplegic (SMAD) family members, and estrogen receptor $\alpha(E R \alpha)$ [8]. Furthermore, mTOR inhibitors, somatostatin analogues, tyrosine kinase inhibitors and epigenetic drugs have shown a significant efficacy in several model of MEN1-related pancreatic neuroendocrine neoplasia [9]. 
MEN1 has shown to be responsible for the encoding of caspase 8 gene, and mice expressing a monoallelic menin express a lower level of caspase 8 than the homozygous [10]. Despite some first evidence of the possible implication of MEN1 in cell death mechanisms, the exact role of menin in apoptotic and alternative apoptotic mechanisms e.g. endoplasmic reticulum (ER) stress-mediated and autophagic cell death has not been described yet. Therefore, the aim of this study was to investigate the interaction between menin and apoptosis.

\section{Results}

\section{Cytotoxic effects of staurosporine}

BON1, QGP1 and HPSC2.2 cell viability was continuously monitored for $120 \mathrm{~h}$ after administration of $100 \mathrm{nM}, 1 \mu \mathrm{M}$ and $10 \mu \mathrm{M}$ of staurosporine. As shown in Fig. $1 \mathrm{~A}, 10 \mu \mathrm{M}$ of staurosporine was responsible for the significant reduction of the cell viability in BON1 cells. Instead, lower concentrations did not affect the cell viability, which showed a curve similar to untreated cells. The administration of $1 \mu \mathrm{M}$ of staurosporine was monitored further by contrast light microscopy showing, in contrast to the cell viability, a reduction of cell attachment and density of BON1 cells after $24 \mathrm{~h}$ and $48 \mathrm{~h}$ of treatment. QGP1 cells (Fig. 1B) seemed not to be affected by $10 \mu \mathrm{M}$ of staurosporine. Instead, the lowest concentration of $100 \mathrm{nM}$ of staurosporine showed a strong reduction of cell viability. Interestingly, the light microscopy image showed a loss of QGP1 attachment after $24 \mathrm{~h}$ and $48 \mathrm{~h}$ of treatment with $1 \mu \mathrm{M}$ of staurosporine.

Pancreatic stellate cells HPSC2.2 showed a reduction of cell viability after treatment with 1 and $10 \mu \mathrm{M}$ of staurosporine. No reduction of cell growth was observed after treatment with $100 \mathrm{nM}$ of staurosporine (Fig. 1C). Light microscopy images confirmed that $24 \mathrm{~h}$ and $48 \mathrm{~h}$ of treatment with $1 \mu \mathrm{M}$ of staurosporine caused a detachment and a reduction of density of HPSC 2.2 cells. The concentration of $1 \mu \mathrm{M}$ of staurosporine was administered to the cells in all further experiments.

\section{Influence of MEN1 and staurosporine on the expression of TP53 and CDKN1A}

An initial transfection with four specific siRNA for MEN1 was performed to select the siRNA with the highest knockdown efficiency (Supplementary Figure). The most efficient siRNA, in terms of MEN1 knockdown (Hs_MEN1_1) was used for the further experiments including the transient inactivation of $M E N 1$. The transfection with the specific siRNA for $M E N 1$ caused a significant reduction (*p-value $<0.05$ ) of MEN1 and TP53 transcripts in BON1 cells; HPSC2.2 cells showed a significant (*p-value $<0.05)$ down-regulation of MEN1, CDKN1A and TP53 (Fig. 1A, C lowest panel). Treatment with $1 \mu \mathrm{M}$ of staurosporine alone and after knock
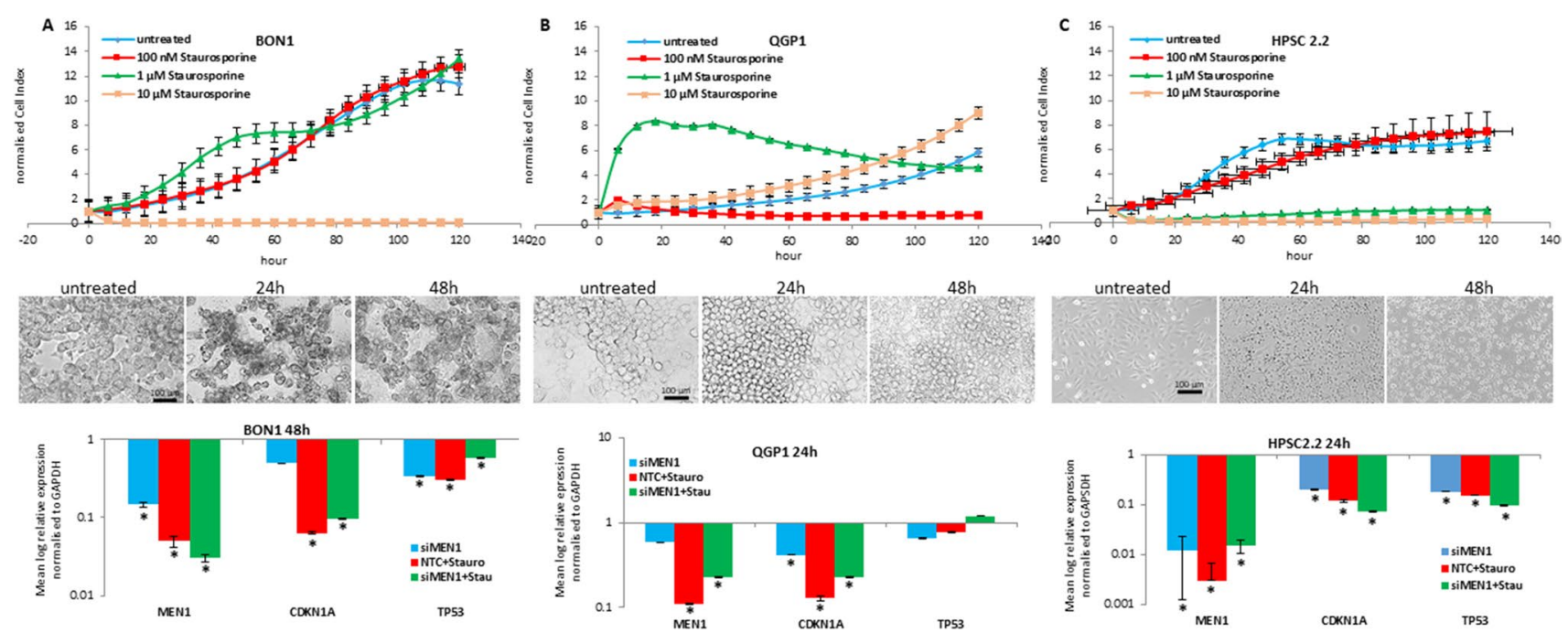

Fig. 1 Effect of staurosporine on cell viability and transcripts expression. BON1 (A), QGP1 (B) and HPSC2.2 (C) cells were cultured in 96-well E-plates and were treated with $100 \mathrm{nM}, 1 \mu \mathrm{M}$ and $10 \mu \mathrm{M}$ of staurosporine after $24 \mathrm{~h}$. Cell impedance was measured continuously for $120 \mathrm{~h}$. Shown are means of normalized cell index \pm SD of three independent experiments performed in triplicates. BON1 (A), QGP1 (B) and HPSC2.2 (C) cells (middle panels) were treated with $1 \mu \mathrm{M}$ of staurosporine for $24 \mathrm{~h}$ and $48 \mathrm{~h}$. Inverted light microscopy pic-

tures magnification is $100 \times$. Scale bar represents $100 \mu \mathrm{m}$. Expression of MEN1, CDKN1A and TP53 transcripts was determined in BON1 (A), QGP1 (B) and HPSC2.2 (C) monolayer cells treated for $24 \mathrm{~h}$ or $48 \mathrm{~h}$ with $1 \mu \mathrm{M}$ of staurosporine and with a siRNA for MEN1 (lower middle panel). Shown are means \pm SEM of three independent experiments performed with biological duplicates. $* \mathrm{p}<0.05$ NTC (negative transfection control) vs siMEN1 or staurosporine treated cells 
down of $M E N 1$ caused a significant $(* \mathrm{p}<0.05)$ reduction of MEN1, CDKN1A and TP53 in BON1 and HPSC2.2 cells. QGP1 cells showed a stable expression of MEN1 transcript after transfection with a siRNA for MEN1. The treatment with $1 \mu \mathrm{M}$ of staurosporine caused a significant reduction of MENI and CDKN1A. TP53 transcript level was stable.

\section{Expression of the caspases after treatment with staurosporine and MEN1 knock down}

The protein level of caspase 8, caspase 3 and Flip was detected in BON1 and HPSC 2.2 cells after MEN1 knock down and exposure to $1 \mu \mathrm{M}$ of staurosporine for $24 \mathrm{~h}$ and $48 \mathrm{~h}$. As shown in Fig. 2A (left panels), the protein level of the uncleaved caspase 8 reduced significantly (p-value $<0.05$ ) after $24 \mathrm{~h}$ of treatment with staurosporine, the knockdown of MENI and their combined administration. The protein level of the $43 / 41 \mathrm{kDa}$ cleaved caspase 8 was significantly down regulated by the treatment with $1 \mu \mathrm{M}$ of staurosporine, the knock down of MEN1 and their combination, whereas the protein level of the $18 \mathrm{kDa}$ cleaved caspase 8 was unchanged. The longer exposure $(48 \mathrm{~h})$ to $1 \mu \mathrm{M}$ of staurosporine caused a significant decrease of the uncleaved caspase 8. Instead, MEN1 knock down caused a significant accumulation of it. The combined administration of staurosporine and siMENI caused a significant decrease of the uncleaved caspase 8 in comparison to untreated cells. The 43/41 kDa cleaved caspase 8 strongly down regulated after exposure to staurosporine, MEN1 knockdown and their combination. Interestingly, the $18 \mathrm{kDa}$ cleaved caspase 8 was up regulated by the treatment with $1 \mu \mathrm{M}$ of staurosporine. Instead, the knockdown of MENI did not modulate its protein level that kept at the level of untreated cells, even after the addition of $1 \mu \mathrm{M}$ of staurosporine. The protein level of the uncleaved caspase 3 (Fig. 2A middle panels) and its cleaved form was significantly up regulated after $24 \mathrm{~h}$ of exposure to $1 \mu \mathrm{M}$ of staurosporine, MEN1 knockdown and their combination. The longer exposure $(48 \mathrm{~h})$ to $1 \mu \mathrm{M}$ of staurosporine, the MENI knockdown and their combination caused a significant decrease of the uncleaved caspase 3 . The protein level of the cleaved caspase 3 increased significantly after treatment with staurosporine. Instead, the knock down of $M E N 1$ caused a decrease of its protein level. The combined administration of $1 \mu \mathrm{M}$ of staurosporine and siMEN1 caused an up regulation of the cleaved caspase 3 as well.

The protein level of FlipL was not detectable in BON1 cells (Fig. 2A, right panels). The FlipS isoform decreased after $24 \mathrm{~h}$ of treatment with $1 \mu \mathrm{M}$ of staurosporine, MENI knockdown and their combination. The longer exposure

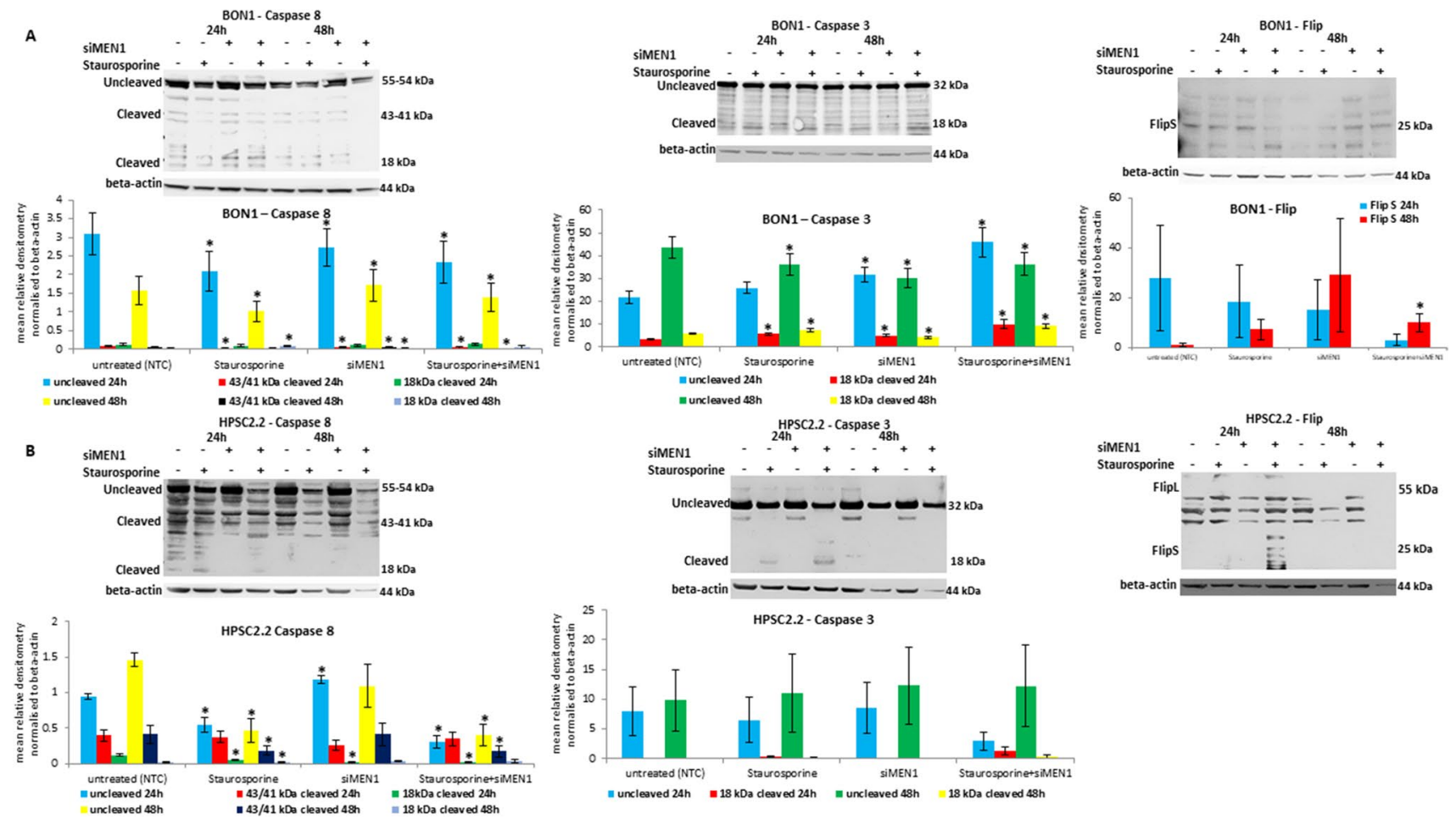

Fig. 2 Staurosporine effect on caspases and Flip after MEN1 knockdown. Expression and densitometry of caspase 8, caspase 3 and Flip in BON1 (A) and HPSC2.2 (B) cells treated for $24 \mathrm{~h}$ and $48 \mathrm{~h}$ with
$10 \mu \mathrm{M}$ of staurosporine and knocked down for MEN1. Densitometry results were normalized to $\beta$-actin content. ${ }^{*} \mathrm{p}<0.05$ NTC (negative transfection control) vs siMEN1 or staurosporine treated cells 
(48 h) to staurosporine and siMEN1 caused an increase of its protein level even after both combined administration.

Human pancreatic stellate cells HPSC2.2 (Fig. 2B, left panels) showed a significant decrease of the uncleaved caspase 8 after $24 \mathrm{~h}$ of treatment with $1 \mu \mathrm{M}$ of staurosporine alone and in combination with siMEN1. Instead, the solo knockdown of MEN1 caused a significant increase of the uncleaved caspase 8 (Fig. 2B, left panels). The level of the $43 / 41 \mathrm{kDa}$ cleaved caspase 8 was unchanged or slightly decreased after solo and combined administration of staurosporine and siMEN1. The protein level of the $18 \mathrm{kDa}$ cleaved form was significantly $(* \mathrm{p}$-value $<0.05)$ reduced by the treatment with staurosporine, siMEN1 and their combined administration. The prolonged treatment with staurosporine $(48 \mathrm{~h})$ caused a significant $(* \mathrm{p}$-value $<0.05)$ reduction of the uncleaved and both cleaved caspase 8 proteins even after knockdown of MEN1. Instead, the single incubation with siRNA for $M E N 1$ did not cause any change of the protein level of all forms of caspase 8 . The protein level of the uncleaved caspase 3 was unchanged after $24 \mathrm{~h}$ of treatment with staurosporine or siMEN1 (Fig. 2B, middle panels). Their combination caused, instead, a reduction of its protein level. The longer exposure ( $48 \mathrm{~h}$ ) caused no change of its protein level. The cleaved form of caspase 3 was modulated neither after $24 \mathrm{~h}$ nor after $48 \mathrm{~h}$ of treatment with $1 \mu \mathrm{M}$ of staurosporine and/or siMEN1. Their combination caused only a slight increase of the cleaved caspase 3 after $24 \mathrm{~h}$ of treatment. FlipL was not detectable (Fig. 2B, right panel). The FlipS isoform was only detectable in HPSC 2.2 cells treated for $24 \mathrm{~h}$ with $1 \mu \mathrm{M}$ of staurosporine and siMEN1. The protein level of caspases and FlipS was densitometrically and statistically (t-test) analyzed and the results included as graphs included below the blots.

\section{Influence of MEN1 on the caspases activity}

BON1 and HPSC2.2 cells were transfected with a siRNA for $M E N 1$ and treated with $1 \mu \mathrm{M}$ of staurosporine for up to $48 \mathrm{~h}$. As shown in Fig. 3A and B, MEN1 knock down or $24 \mathrm{~h}$ of treatment with $1 \mu \mathrm{M}$ of staurosporine caused a significant $(*$ p-value $<0.05$ ) up-regulation of caspase 8 activity. Instead, the activity of caspase 8 was significantly $(\# \mathrm{p}<0.05)$ reduced by the combination of MEN1 knockdown and staurosporine. ZVAD, a potent pan-caspase inhibitor, hampered the staurosporine-mediated activity of caspase 8 . The activity of the executioner caspases 3 and 7 was further modulated by $48 \mathrm{~h}$ of treatment with $1 \mu \mathrm{M}$ of staurosporine. BON1 cells showed an up-regulation of caspases 3/7 (Fig. 3C) after treatment with $1 \mu \mathrm{M}$ of staurosporine. MEN1 knockdown did not affect the efficacy of staurosporine. ZVAD reduced the caspase activity at lower level than the untreated sample. Instead, HPSC2.2 cells
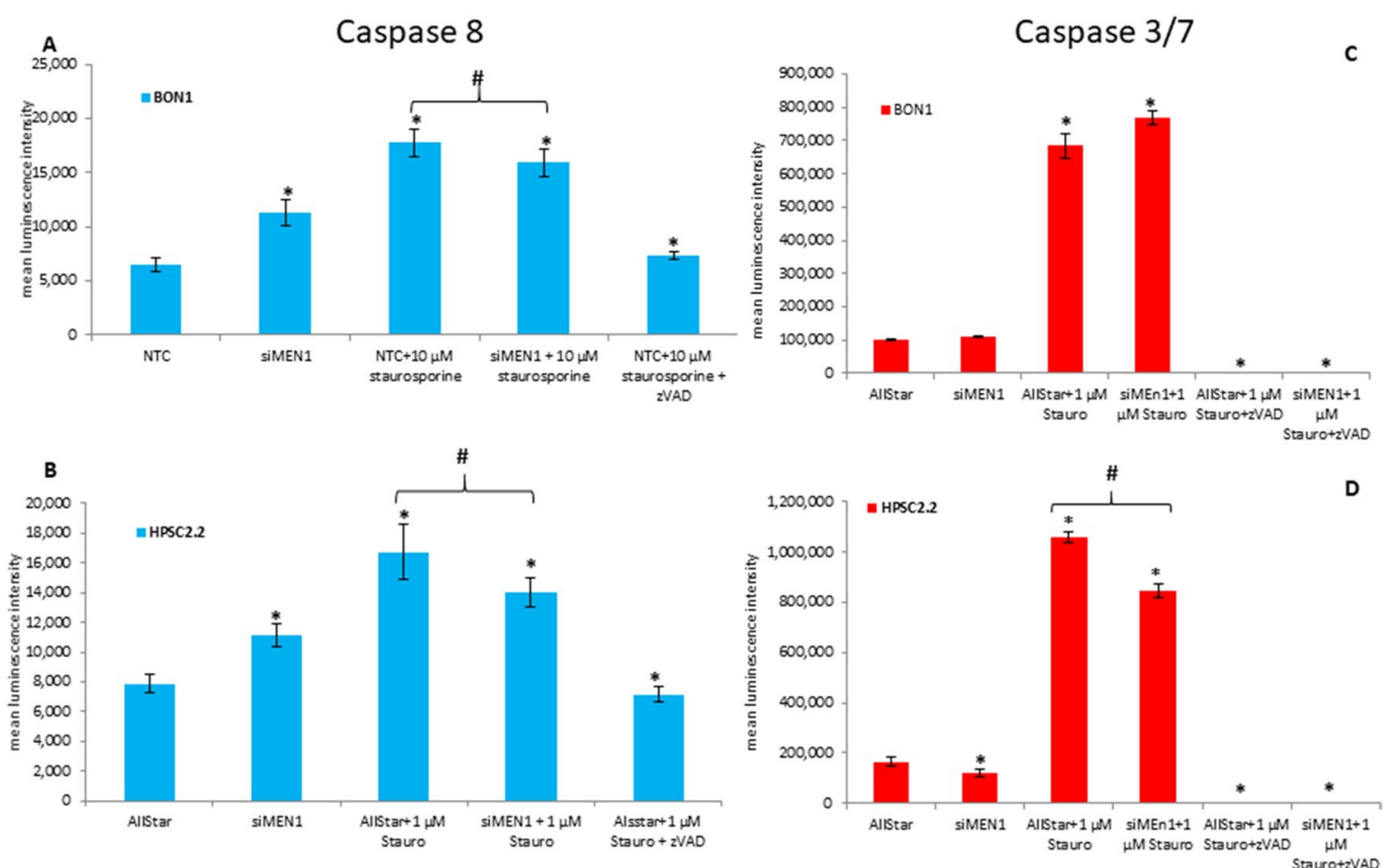

Fig. 3 Caspases activity after MEN1 knock down and staurosporine administration. Analysis of caspases 8 and 3/7 activity in BON1 (A, C) and HPSC2.2 (B, D) cells. ZVAD was included as negative con- trol of caspase activity. ${ }^{*} \mathrm{p}<0.05$ NTC (negative transfection control) vs siMEN1 or staurosporine treated cells. $\#$ p $<0.05$ staurosporine vs siMEN1+ staurosporine 
showed a significant $(*$ p-value $<0.05)$ reduction of caspases 3/7 after MEN1 knockdown (Fig. 3D). Furthermore, MENI knockdown was able to block, significantly (\#p $<0.05$ ), the staurosporine-mediated hyper activation of the caspases. Once again, zVAD inhibited the activation of the caspases mediated by the treatment with $1 \mu \mathrm{M}$ of staurosporine.

\section{Effect of staurosporine on MEF monolayer and spheroids}

Spheroids derived from $\mathrm{MENI}^{+/+}$and $\mathrm{MENI}^{-/-}$MEFs were treated for $72 \mathrm{~h}$ with $1 \mu \mathrm{M}$ of staurosporine (Fig. 4A). The $\mathrm{MENI}^{+/+}$spheroids showed a significant (*p-value $\left.<0.05\right)$ reduction of their size already after $24 \mathrm{~h}$ of treatment. The shrinking of the size was significant at all treatment time points. Instead, the $M E N 1^{-1-}$ spheroids showed no significant reduction of their size, even after $72 \mathrm{~h}$ of treatment with $1 \mu \mathrm{M}$ of staurosporine. The Fig. 4B highlights that the treatment with $1 \mu \mathrm{M}$ of staurosporine caused a reduction of the size, a loss of the integrity of the outer membrane and a dismantling of the ultrastructure of $\mathrm{MEN1}^{+/+}$spheroids. Instead, $\mathrm{MENI}^{-/-}$spheroids were not affected by the treatment with $1 \mu \mathrm{M}$ of staurosporine, they kept their ultrastructure and their outer membrane was intact. A small reduction of their size was the only detectable effect. $M E N 1^{+/+}$ and $\mathrm{MENI}^{-/-}$monolayer MEFs were tested for the caspases activity. As shown in Fig. 4C, $48 \mathrm{~h}$ of treatment with $1 \mu \mathrm{M}$ of staurosporine caused a significant $(* \mathrm{p}<0.05)$ increase of the caspases 8 and 3/7 in $M E N 1^{+/+}$fibroblasts. Instead, $\mathrm{MEN1}^{-/-}$cells showed no increase of the caspases activity after treatment with staurosporine, which was significantly $(\# \mathrm{p}<0.05)$ lower in comparison with $\mathrm{MENI}^{+/+}$cells. ZVAD was able to inhibit significantly $\left({ }^{*} \mathrm{p}<0.05\right)$ the activation of the caspases in the $\mathrm{MENI}^{+/+}$cells.

The uncleaved protein level of caspase 8 (Fig. 4D, E) slightly reduced in both MEFs after $24 \mathrm{~h}$ of treatment with staurosporine. The prolonged treatment $(48 \mathrm{~h})$ with $1 \mu \mathrm{M}$ of staurosporine caused a significant $(\mathrm{p}$-value $<0.05)$ increase of uncleaved caspase 8 protein level in $\mathrm{MENI}^{-/-}$cells. The $43 / 41 \mathrm{kDa}$ cleaved caspase 8 increased significantly in $\mathrm{MENI}^{+/+}$cells, whereas decreased significantly in $M E N 1^{-1-}$ cells after $24 \mathrm{~h}$ of treatment with $1 \mu \mathrm{M}$ of staurosporine. The longer exposure to staurosporine caused no significant change of its protein level in $M E N 1^{+/+}$

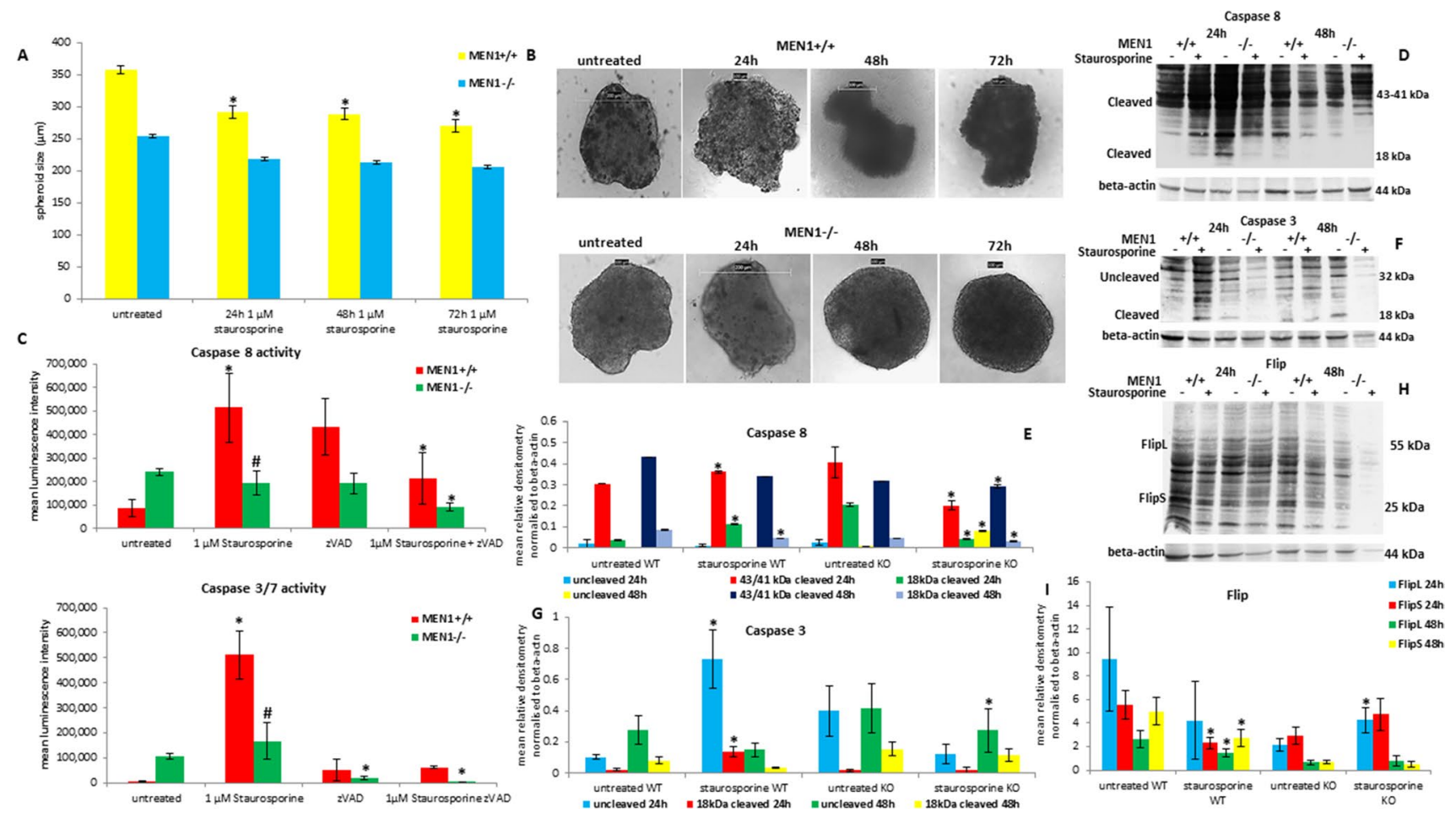

Fig. 4 Effects of staurosporine in mouse embryo fibroblasts lacking $M E N 1$ expression. $M E N 1^{+/+}$and $\mathrm{MEN1}^{-/-}$mouse embryo fibroblasts spheroids size (A) was measured after $24 \mathrm{~h}, 48 \mathrm{~h}$ and $72 \mathrm{~h}$ of treatment with $1 \mu \mathrm{M}$ of staurosporine. Shown are means \pm S.D. of the size of 9 spheroids. ${ }^{*} \mathrm{p}<0.05$ untreated vs staurosporine treated spheroids. Light contrast microscopy of $\mathrm{MEN1}^{+/+}$and $\mathrm{MEN1}^{-/-} \mathrm{MEF}$ spheroids (B) after $24 \mathrm{~h}, 48 \mathrm{~h}$ and $72 \mathrm{~h}$ of treatment with $10 \mu \mathrm{M}$ of staurosporine. Caspase 8 and caspase $3 / 7$ activity (C) of $M E N 1^{+/+}$ and $\mathrm{MEN1}^{-/-}$MEF monolayer treated for $48 \mathrm{~h}$ with $1 \mu \mathrm{M}$ of staurosporine. Shown are means \pm S.D. of experiments performed in triplicates. $* \mathrm{p}<0.05$ untreated vs staurosporine treated cells. Protein detection and densitometry of caspase $8(\mathbf{D}, \mathbf{E})$, caspase $3(\mathbf{F}, \mathbf{G})$ and Flip $(\mathbf{H}, \mathbf{I})$. Densitometry results were normalized to $\beta$-actin content. $* \mathrm{p}<0.05$ untreated vs staurosporine treated cells. $\# \mathrm{p}<0.05 \mathrm{MENI}^{+/+}$ vs $\mathrm{MEN1}^{-1-}$ 
cells, and its level was significant (p-value $<0.05)$ stable in $\mathrm{MEN1}^{-/-}$fibroblasts. The $18 \mathrm{kDa}$ cleaved form of caspase 8 was characterized by a significant up-regulation in $\mathrm{MENI}^{+/+}$fibroblasts; instead, it decreased significantly in $M E N 1^{-/-}$fibroblasts after $24 \mathrm{~h}$ of exposure to $1 \mu \mathrm{M}$ of staurosporine. The $48 \mathrm{~h}$ treatment caused a significant decrease of the $18 \mathrm{kDa}$ cleaved form in both MENI wild type and knocked out fibroblasts. Caspase 3 showed a significant up-regulation of its uncleaved ( $32 \mathrm{kDa})$ and cleaved form $(18 \mathrm{kDa})$ in $M E N I^{+/+}$cells after $24 \mathrm{~h}$ of treatment with $1 \mu \mathrm{M}$ of staurosporine. The level of both proteins reduced after long time exposure $(48 \mathrm{~h})$. Interestingly, caspase 3 showed a down-regulation of both uncleaved and cleaved forms in $\mathrm{MEN1}^{-/-}$fibroblasts after $24 \mathrm{~h}$ and $48 \mathrm{~h}$ of exposure to $1 \mu \mathrm{M}$ of staurosporine (Fig. 4F, G). Both L and S isoforms of Flip were significantly down regulated in $\mathrm{MENI}^{+/+}$fibroblasts after $24 \mathrm{~h}$ and $48 \mathrm{~h}$ of treatment with $1 \mu \mathrm{M}$ of staurosporine. $M E N 1^{-/-}$fibroblasts showed, after $24 \mathrm{~h}$ of exposure, an increase of both isoforms, whereas no changes have been observed after $48 \mathrm{~h}$ of exposure to $1 \mu \mathrm{M}$ of staurosporine (Fig. 4H, I). The protein level was densitometrically and statistically (t-test) analyzed and the results included as graphs included below the blots.

\section{Implication of MEN1 in staurosporine-mediated apoptotic cell death}

The $\mathrm{MENI}^{+/+}$and $\mathrm{MENI}^{-/-}$MEFs were treated for up to $72 \mathrm{~h}$ with 1 and $10 \mu \mathrm{M}$ of staurosporine. The micrographs (Fig. 5 upper panels) show that $\mathrm{MENI}^{+/+}$MEFs were strongly affected by the cytotoxicity of both concentrations of staurosporine already after $24 \mathrm{~h}$ of treatment. The prolonged treatment caused a further reduction of the cell number and the appearance of the typical apoptotic sub-cellular products, e.g. blebbing, apoptotic bodies and finally pyknosis. Instead, the $\mathrm{MENI}^{-/-}$MEFs were only characterized by a reduction of cell number. No apoptotic effects could be observed. Furthermore, the ongoing apoptosis could be proven in $\mathrm{MENI}^{+/+}$MEFs by the luminescence-based measurement of phosphatidylserine (PS) exposure and by the fluorescence-based (DNA-binding green fluorescent dye) measurement of secondary necrosis (Fig. 5 lower panels). These cells evidenced an increase of PS exposure after $24 \mathrm{~h}$ of treatment with both concentrations of staurosporine accompanied by an increase of the secondary necrosis after $48 \mathrm{~h}$ of treatment, thus confirming that the cells are dying by apoptosis. Instead, the untreated cells showed only an increase of PS, which was followed by an absent necrosis fluorescent signal. Interestingly, the $M E N 1^{-/-}$MEFs evidenced a weak/ absent increase of the PS exposure luminescent signal after the administration of both concentrations of staurosporine at all treatment time points, especially in comparison to the luminescent signal of untreated cells. Furthermore, the necrosis fluorescent signal detected in $\mathrm{MEN1}^{-/-}$MEFs was weak in both untreated and staurosporine treated cells in comparison to $\mathrm{MENI}^{+/+}$MEFs (Fig. 5 lower panels).

These results highlight that the lack of MENI confers the MEFs the resistance to the staurosporine cytotoxicity. These cells are able, after short time, to overcome the cytotoxicity caused by the treatment with staurosporine and in particular to survive to apoptosis.

\section{Discussion}

Impairment of MEN1 expression caused by mutation is responsible for the development of benign neoplasia of the parathyroid, pituitary and adrenocortical glands and further pancreatic neuroendocrine neoplastic lesions. MEN1 mutation represents the most frequent alteration in pancreatic neuroendocrine malignancies [3]. It has been shown that MEN1 is implicated in the regulation of factors involved in several cellular processes, e,g, cell proliferation, differentiation and death $[3,7]$. However, its pro-death role has not been well defined yet. The first evidence of its implication in cell fate decision has been demonstrated in mouse embryo fibroblasts. The ectopic expression of menin, the protein encoded by $M E N 1$, was responsible to mediate apoptosis by modulating the pro-apoptotic factors Bax and Bak [11]. Further evidence highlighted that point mutations occurring at MEN1 impair its ability to promote the transcription of caspase 8 gene [12] and TNF-alpha-mediated apoptosis [10]. Furthermore, treatment with enalapril and aspirin increased the expression of caspase 3 in $M E N I^{+/ T}$ knock out mouse model [13]. The present study focused on the role exerted by MENI under proapoptotic condition mediated by the treatment with staurosporine, a canonical apoptosis inducer in solid malignancies [13-16]. Transiently knockdown of MEN1 caused a significant down-regulation of CDKN1A and TP53 transcripts, as well as after treatment with staurosporine, proving a direct correlation between $M E N 1$ and the master regulators of cell fate as previously found in gamma-irradiated rat insulinoma cells where, MEN1 mutated variants lowered the apoptotic response [17]. Additional findings evidenced that the treatment with meninMLL inhibitor caused the restoration of proliferation mediated by suppression of $C D K N 1 A, C D K N 1 B$ and $C D K N 2 C$ in human pancreatic beta cells [18]. Furthermore, the knockdown of $M E N 1$ was responsible for the down-regulation of caspase 8 activity in human insulinoma cells and human pancreatic stellate cells. In addition, the stellate cells showed a down-regulation of the caspase 3 activity after MENI knock down. These findings were further supported by the significant down-regulation of the protein level of the cleaved form of the caspases 8 and 3 in MENI knocked down human cells treated with staurosporine. Additionally, the accumulation of the anti-apoptotic FlipS isoform confirmed that MENI knockdown impedes cell 


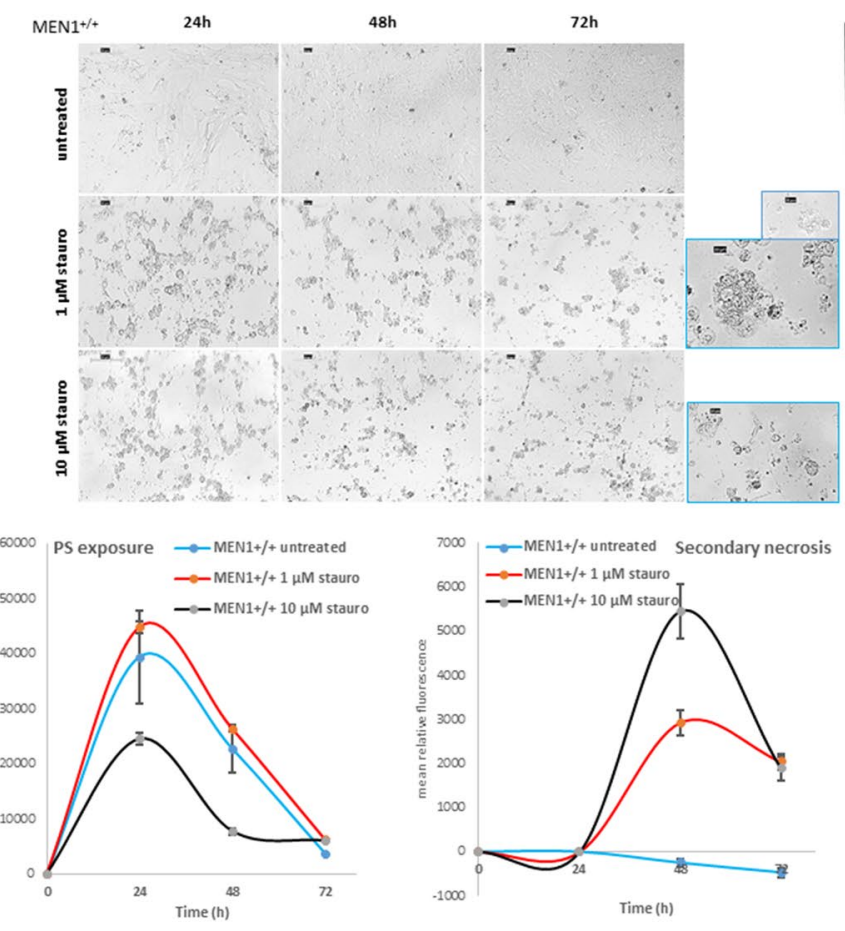

Fig. 5 Detection of apoptosis in $\mathrm{MEN1}^{+/+}$and $\mathrm{MEN1}^{-/-} \mathrm{MEFs}$. (Upper panels) Micrographs of $M E N 1^{+/+}$and $M E N 1^{-/-}$MEFs after the administration of 1 and $10 \mu \mathrm{M}$ of staurosporine for up to $72 \mathrm{~h}$. Higher magnification miniatures (blue frame) highlight the appearance of blebbing, apoptotic bodies and pyknosis in $\mathrm{MEN1}^{+/+} \mathrm{MEFs}$ and their absence in $M E N 1^{-1-}$ MEFs. Scale bars are 50 and $20 \mu \mathrm{m}$. Magnification is $200 \times$ and $400 \times$. (Lower panels) Detection of the

demise, especially in human insulinoma cells. Thus introducing a new regulatory mechanism of MEN1 on the activity of caspases and expanding the previously described role as promoter of caspase 8 gene expression. Further results highlighted the role exerted by MEN1 on the modulation of caspases. Interestingly, the knockout of MEN1 in mouse embryo fibroblasts sustained these cells for being resistant to the prodeath treatment with staurosporine. As well, spheroids derived from $\mathrm{MEN1}^{-/-}$fibroblasts were not perturbed by treatment with staurosporine, keeping an intact ultrastructure and a stable outer spheroid membrane. Furthermore, the loss of MENI determined a down-regulation of both caspase 8 and caspase 3 activity and the protein level of their cleaved forms. Additionally, the two Flip isoforms $\mathrm{L}$ and $\mathrm{S}$, exerting a fine tuned role in the modulation of apoptosis [19], were up regulated supporting that the loss of MEN1 inhibits the activation of pro-apoptotic players and let stabilize the anti-apoptotic markers. Further results evidenced that the lack of MEN1 impeded, in MEFs, the exposure of phosphatidylserine and the secondary necrosis after the administration of staurosporine. Instead, the expression of MENI determined, in staurosporine-treated MEFs, the accumulation of apoptotic bodies and the blebbing together with the increase of PS exposure and secondary necrosis.

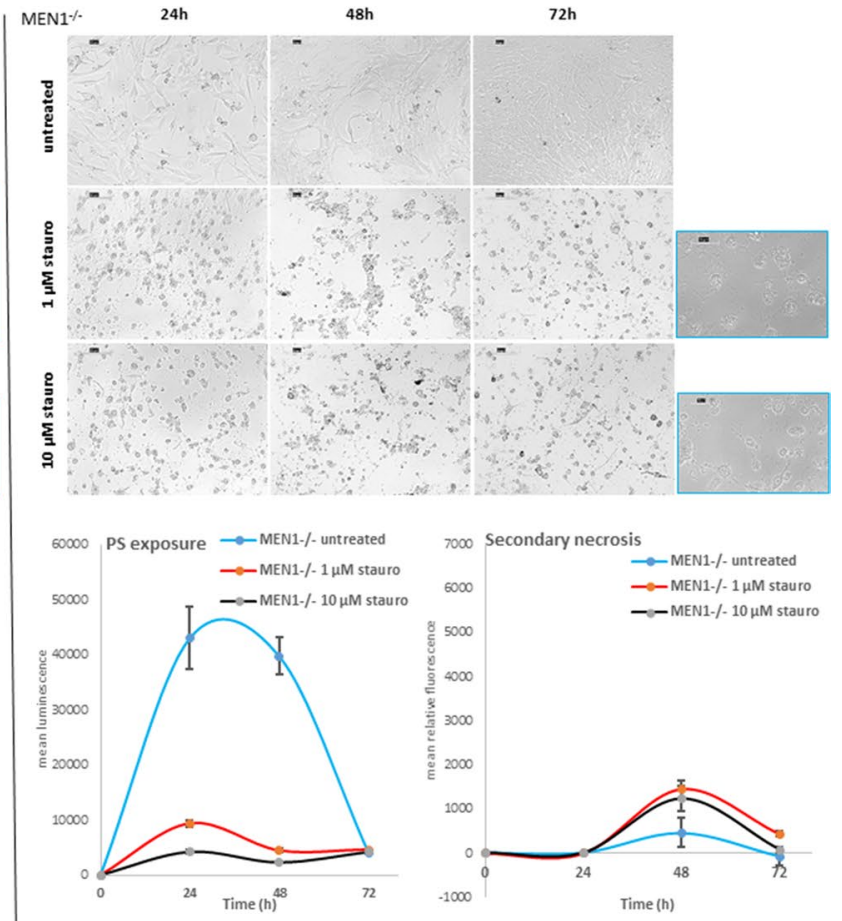

luminescent signal of phosphatidylserine (PS) exposure and the fluorescent signal of secondary necrosis in $\mathrm{MEN1}^{+/+}$and $\mathrm{MEN1}^{-/-} \mathrm{MEFs}$ after the administration of 1 and $10 \mu \mathrm{M}$ of staurosporine for up to $72 \mathrm{~h}$. Shown are means of relative luminescence and fluorescence normalized to blank \pm SEM of experiments performed in quadruplicates

In summary, this study shows that MEN1 controls the activity of the initiator caspase 8 and the executioner caspase 3 in human and murine cells. Furthermore, the knockdown of $M E N 1$ caused a significant down-regulation of CDKN1A and TP53 transcripts. Further studies need to confirm the relevance of these results in $M E N 1$ patients.

\section{Conclusion}

The present study indicates that menin exerts an influence on the apoptotic-signaling pathway. Loss of menin blocks the apoptotic process. These new insights could highlight new therapeutic approaches in MEN1 patients.

\section{Methods and materials}

\section{Cell culture}

Human insulinoma BON1, and pancreatic stellate cells HPSC2.2 were a kindly gift from Heidi Griesmann (Department of Gastroenterology, University Hospital Halle, Germany) and Malte Buchholz (Department of Gastroenterology, Philipps University Marburg Germany). The cells were 
grown in DMEM (Gibco, Paisley, UK) supplemented with $10 \%$ fetal bovine serum, penicillin (100 Units/ml) and streptomycin $(100 \mu \mathrm{g} / \mathrm{ml})$ at $37^{\circ} \mathrm{C}$ in a humidified atmosphere containing $5 \% \mathrm{CO}_{2}$. The human somatostatinoma cell line QGP1 (Malte Buchholz) were grown in RPMI Medium 1640 (Gibco® by Life Technologies ${ }^{\mathrm{TM}}$, Carlsbad, USA), with $10 \%$ fetal bovine serum, penicillin (100 Units/ml) and streptomycin $(100 \mu \mathrm{g} / \mathrm{ml}) . M E N 1^{+/+}$and $\mathrm{MENI}^{-/-}$mouse embryo fibroblasts, a kindly gift from Philippe Bertolino and Chang X. Zhang (Cancer Research Center of Lyon, France) [20], were grown in DMEM (Gibco) supplemented with $10 \%$ fetal bovine serum, penicillin (100 Units $/ \mathrm{ml}$ ) and streptomycin $(100 \mu \mathrm{g} / \mathrm{ml})$ at $37^{\circ} \mathrm{C}$ in a humidified atmosphere containing $5 \% \mathrm{CO}_{2}$.

\section{Substances}

Staurosporine (SIGMA-ALDRICH, St Louis USA) and the Caspase Inhibitor zVAD-FMK (R\&D Systems, Minneapolis USA) were dissolved in sterile DMSO (WAK-Chemie Medical GmbH, Steinbach Germany).

\section{Real-time cell viability analysis}

BON1, QGP1 and HPSC2.2 cells were cultured on E-plates (05232368001, OLS, Bremen, Germany) and real-time cell viability was measured after treatment with $100 \mathrm{nM}, 1 \mu \mathrm{M}$ and $10 \mu \mathrm{M}$ staurosporine by xCELLigence RTCA system (Roche, Basel Switzerland). XCELLigence continuously measured $(120 \mathrm{~h})$ the impedance to quantify the adherence of the cells on the plate's electrodes.

\section{MEN1 transient knockdown}

Four specific siRNA targeting the transcript of MENI (SI00630231, FlexiTube GeneSolution GS4221 for MEN1 Qiagen, Hilden, Germany) were used to perform the transient knockdown of MEN1 in human pancreatic cells BON1, QGP1 and pancreatic stellate cells HPSC2.2. The cells were transfected by following the fast transfection protocol suggested by the manufacturer (Qiagen). HiPerfect (Qiagen) was used as transfection reagent and mixed together with the specific siRNAs and serum free medium by following the manufacturer instrctions. The cells were first seeded with complete growth medium and then the transfection mixture was added. The knockdown was monitored by RTqPCR after $48 \mathrm{~h}$ of transfection. The siRNA with the highest knockdown efficiency (Hs_MEN1_2, SI00630238, Qiagen) was used for the further experiments. A negative transfection control (NTC, Qiagen) was included in all experimental settings including the MEN1 knockdown.

\section{Quantitative RT-PCR}

Total RNA was isolated with the RNeasy Mini Kit (74106, QIAGEN, Hilden Germany) according to the manufacturer`s protocol. Reverse Transcription of mRNA was performed with iScript ${ }^{\mathrm{TM}}$ cDNA Synthesis Kit (170-8891, Bio-Rad Laboratories, Hercules, USA) on FlexCycler (Analytik Jena AG, Jena, Deutschland). Qiagen primers for human MEN1 (QT00064848), CDKN1A (QT00062090), TP53 (QT00060235) and GAPDH (QT01192646) were used with GoTaq ${ }^{\circledR}$ qPCR Master Mix (Promega, Madison, USA) on RT-qPCR thermocycler CFX96 ${ }^{\text {TM }}$ Real-Time System (BioRad Laboratories). Results were analysed with the Bio-Rad CFX-Manager (Bio-Rad Laboratories) and normalized with GAPDH mRNA content for each sample. Raw data were further analysed with Rest2009 (relative Expression Software Tool V.2.0.13. Qiagen).

\section{Western blot analysis}

Whole cell lysates were prepared with Jie's Buffer $(10 \mathrm{mM}$ $\mathrm{NaCl}$, 0.5\% NonidetP40, $20 \mathrm{mM}$ Tris-HCL pH7.4, $5 \mathrm{mM}$ $\mathrm{MgCl}_{2}, 1 \mathrm{mM}$ PMSF, Complete Protease Inhibitor and Phosphatase Inhibitor (Roche). The proteins were separated through SDS-Page (NP0342, Life Technologies, Carlsbad, California USA) and transferred to nitrocellulose membranes (10600009, GE Healthcare Life science, Chicago, USA) by semi-dry-blotting with Trans-Blot ${ }^{\circledR}$ Turbo $^{\mathrm{TM}}$ Transfer System (Bio-Rad Laboratories). The membranes were further sliced according to the required molecular weight of the proteins of interest, blocked in 4\% BSA (23208, Thermo Fisher Scientific, Waltham MA USA) in TBS-Tween $20(0.5 \%)$ and incubated with primary antibodies against Caspase 8 (ALX804-242, Enzo Life Sciences GmbH, Lörrach Germany), Caspase 3 (NB100-56708, Novus Biologicals, Abingdon UK), Flip (ALX-804-961-0100, Enzo Life Sciences), $\beta$-actin (A5441 SIGMA-ALDRICH, St Louis USA) and GAPDH (ab9485, AbCam). Bound primary antibodies were detected by secondary horseradish-labelled goat anti-rabbit (A0545, SIGMA-ALDRICH), goat anti-mouse (A9917, SIGMAALDRICH) antibodies and SuperSignal West Pico Chemiluminiscent Substrate (Thermo Fisher Scientific, Waltham, USA). The immuno-detection was quantified using Fusion image capture (VILBER LOURMAT Deutschland GmbH, Eberhardzell, Germany) and Bio-1D analysis System (VILBER LORUMAT Deutschland GmbH).

\section{Caspase activity detection}

The cells were seeded in 96-well cell culture plates and transfected with the siRNA for MEN1. Caspase activity was determined after treatment with staurosporine (6-48 h) 
with the Caspase Glo-8 (G8200) and the Caspase Glo-3/7 (G8090) assays from Promega by following the manufacturer instructions.

\section{Establishing of MEF-derived spheroids}

$\mathrm{MENI}^{+/+}$and $\mathrm{MENI}^{-/-}$mouse embryo fibroblasts spheroids were formed on $50 \mu 1$ 1.5\% peqGOLD Universal Agarose (PEQLAB Biotechnology GmbH, Erlangen, Deutschland) in a flat-bottom 96-well plate (SARSTEDT AG and Co. KG, Nümbrecht, Germany) for 6 days without medium change [21]. MEFs were placed on an orbital shaker with a shaking speed of $40 \mathrm{rpm}$ overnight. Before treatment, $100 \mu \mathrm{l}$ of medium were removed from each well containing a single spheroid. $100 \mu \mathrm{l}$ medium with staurosporine were added to the remaining $100 \mu \mathrm{l}$ medium. The working concentration was $10 \mu \mathrm{M}$ staurosporine. The micrographs were acquired by inverted microscope Leica (Wetzlar, Germany) with a Leica EC3 camera and digitalized by the software LAS EZ version 2.1.0.

\section{Measurement of apoptosis/necrosis}

The detection of apoptosis/necrosis was performed by luminescence/fluorescence after the administration of the RealTime-Glo ${ }^{\mathrm{TM}}$ Annexin V Apoptosis and Necrosis Assay (JA1011, Promega). 10,000 MEFs (MEN1 + / + and MEN1-/-) were seeded in a 96-well plate. After $24 \mathrm{~h}$, staurosporine was added to the cells at the final concentration of 1 and $10 \mu \mathrm{M}$. The measurement was acquired by FLUOstar OPTIMA (BMG LABTECH, Ortenberg Germany) plate reader for up to $72 \mathrm{~h}$. The date were analyzed by Excel 2016 (Microsoft).

\section{Statistical analysis}

T-test was calculated in order to determine the statistical significance of the results. $p<0.05$ value was regarded as significant. The data analysis was performed by Excel 2016 (Microsoft, Redmond, WA USA).

Supplementary Information The online version contains supplementary material available at https://doi.org/10.1007/s10495-021-01700-1.

Acknowledgements We are thankful to Silvia Roth, Carmen Bollmann and Lena Cook for their technical assistance during the experimental procedures and for collecting and providing the tumour samples. Heidi Griesmann (University Hospital Halle) for providing the BON1, the QGP1 and the HPSC2.2 cells.

Author contribution NW, PB, CXZ: data acquisition; NW, MB, PD: analysis and interpretation of the data; NW, PD: writing the draft and revising it; $\mathrm{MB}, \mathrm{PB}, \mathrm{CXZ}$ : revising the manuscript; $\mathrm{PD}$ : concept and design of the study. All authors read the manuscript and approved the final submission.

Funding Open Access funding enabled and organized by Projekt DEAL. The study was granted by university internal support. No third party support was used.

\section{Declarations}

Conflict of interest The authors declare no conflict.

Open Access This article is licensed under a Creative Commons Attribution 4.0 International License, which permits use, sharing, adaptation, distribution and reproduction in any medium or format, as long as you give appropriate credit to the original author(s) and the source, provide a link to the Creative Commons licence, and indicate if changes were made. The images or other third party material in this article are included in the article's Creative Commons licence, unless indicated otherwise in a credit line to the material. If material is not included in the article's Creative Commons licence and your intended use is not permitted by statutory regulation or exceeds the permitted use, you will need to obtain permission directly from the copyright holder. To view a copy of this licence, visit http://creativecommons.org/licenses/by/4.0/.

\section{References}

1. Thakker RV, Newey PJ, Walls GV, Bilezikian J, Dralle H, Ebeling PR et al (2012) Clinical practice guidelines for multiple endocrine neoplasia type 1 (MEN1). J Clin Endocrinol Metab 97(9):2990-3011

2. Manoharan J, Albers MB, Bartsch DK (2017) The future: diagnostic and imaging advances in MEN1 therapeutic approaches and management strategies. Endocr Relat Cancer 24(10):T209-T225

3. Scarpa A, Chang DK, Nones K, Corbo V, Patch AM, Bailey P et al (2017) Whole-genome landscape of pancreatic neuroendocrine tumours. Nature 543(7643):65-71

4. Jiao Y, Shi C, Edil BH, de Wilde RF, Klimstra DS, Maitra A et al (2011) DAXX/ATRX, MEN1, and mTOR pathway genes are frequently altered in pancreatic neuroendocrine tumors. Science 331(6021):1199-1203

5. Falchetti A (2017) Genetics of multiple endocrine neoplasia type 1 syndrome: what's new and what's old. F1000Res. https://doi. org/10.12688/f1000research.7230.1

6. Wautot V, Khodaei S, Frappart L, Buisson N, Baro E, Lenoir GM et al (2000) Expression analysis of endogenous menin, the product of the multiple endocrine neoplasia type 1 gene, in cell lines and human tissues. Int J Cancer 85(6):877-881

7. Matkar S, Thiel A, Hua X (2013) Menin: a scaffold protein that controls gene expression and cell signaling. Trends Biochem Sci 38(8):394-402

8. Qiu W, Christakis I, Stewart AA, Vodopivec DM, Silva-Figueroa $\mathrm{A}$, Chen $\mathrm{H}$ et al (2017) Is estrogen exposure a protective factor for pancreatic neuroendocrine tumours in female patients with multiple endocrine neoplasia syndrome type 1? Clin Endocrinol (Oxf) 86(6):791-797

9. Grozinsky-Glasberg S, Lines KE, Avniel-Polak S, Bountra C, Thakker RV (2020) Preclinical drug studies in MEN1-related neuroendocrine neoplasms (MEN1-NENs). Endocr Relat Cancer 27(9):R345-R355

10. La P, Yang Y, Karnik SK, Silva AC, Schnepp RW, Kim SK et al (2007) Menin-mediated caspase 8 expression in 
suppressing multiple endocrine neoplasia type 1. J Biol Chem 282(43):31332-31340

11. Schnepp RW, Mao H, Sykes SM, Zong WX, Silva A, La P et al (2004) Menin induces apoptosis in murine embryonic fibroblasts. J Biol Chem 279(11):10685-10691

12. La P, Desmond A, Hou Z, Silva AC, Schnepp RW, Hua X (2006) Tumor suppressor menin: the essential role of nuclear localization signal domains in coordinating gene expression. Oncogene 25(25):3537-3546

13. Manoharan J, Fendrich V, Di Fazio P, Bollmann C, Roth S, Joos B et al (2018) Chemoprevention with enalapril and aspirin in Men1 $(+/ T)$ knockout mouse model. Neuroendocrinology 107(3):257-266

14. Xue LY, Chiu SM, Oleinick NL (2003) Staurosporine-induced death of MCF-7 human breast cancer cells: a distinction between caspase-3-dependent steps of apoptosis and the critical lethal lesions. Exp Cell Res 283(2):135-145

15. del Solar V, Lizardo DY, Li N, Hurst JJ, Brais CJ, Atilla-Gokcumen GE (2015) Differential regulation of specific sphingolipids in colon cancer cells during staurosporine-induced apoptosis. Chem Biol 22(12):1662-1670

16. Manns J, Daubrawa M, Driessen S, Paasch F, Hoffmann N, Löffler A et al (2011) Triggering of a novel intrinsic apoptosis pathway by the kinase inhibitor staurosporine: activation of caspase- 9 in the absence of Apaf-1. FASEB J 25(9):3250-3261

17. Bazzi W, Renon M, Vercherat C, Hamze Z, Lacheretz-Bernigaud A, Wang H et al (2008) MEN1 missense mutations impair sensitization to apoptosis induced by wild-type menin in endocrine pancreatic tumor cells. Gastroenterology 135(5):1698-709. e2

18. Pahlavanneshan S, Behmanesh M, Oropeza D, Furuyama K, Tahamtani Y, Basiri M et al (2020) Combined inhibition of menin-MLL interaction and TGF- $\beta$ signaling induces replication of human pancreatic beta cells. Eur J Cell Biol 99(5):151094

19. Hughes MA, Powley IR, Jukes-Jones R, Horn S, Feoktistova M, Fairall L et al (2016) Co-operative and hierarchical binding of c-FLIP and caspase-8: a unified model defines how c-FLIP isoforms differentially control cell fate. Mol Cell 61(6):834-849

20. Gherardi S, Ripoche D, Mikaelian I, Chanal M, Teinturier R, Goehrig D et al (2017) Menin regulates Inhbb expression through an Akt/Ezh2-mediated H3K27 histone modification. Biochim Biophys Acta Gene Regul Mech 1860(4):427-437. https://doi.org/10. 1016/j.bbagrm.2017.02.003

21. Wong C, Vosburgh E, Levine AJ, Cong L, Xu EY (2012) Human neuroendocrine tumor cell lines as a three-dimensional model for the study of human neuroendocrine tumor therapy. J Vis Exp (66):e4218. https://doi.org/10.3791/4218

Publisher's Note Springer Nature remains neutral with regard to jurisdictional claims in published maps and institutional affiliations. 